\title{
SELECTION ON BILL CHARACTERS IN A POPULATION OF DARWIN'S FINCHES: GEOSPIZA CONIROSTRIS ON ISLA GENOVESA, GALÂPAGOS
}

\author{
B. R. GRANT \\ Division of Biological Sciences, University of Michigan, Ann Arbor, MI 48109-1048
}

\begin{abstract}
Lande and Arnold's (1983) technique for measuring selection on correlated quantitative traits was used to identify the targets of selection and to reveal the direction of selection on three bill dimensions, during different stages of the life cycle in a population of Darwin's finches, Geospiza conirostris, on Isla Genovesa, Galápagos. There was a tendency towards disruptive selection during dry conditions, arising from differential survival. In terms of longevity and breeding success of females, the direction of selection was to increase bill length. For males competing for territories, selection acted to increase bill depth and bill length. The effects of male-male interactions were separated from those of female choice. Male-male interactions selected for deep and long bills, whereas females chose their mates on the basis of a male's territory position and plumage coloration. The results reveal three factors constraining changes in bill dimensions: a tendency for the mean of a dimension to shift in one direction is counteracted by selection in the opposite direction on 1) another, positively correlated, bill dimension, 2) the same dimension in the other sex, and 3) the same dimension at another stage of the life cycle. If these factors are overcome by strong directional selection at one stage of the life cycle and relaxation at another, there can be an evolutionary response because the bill dimensions in this population are known to be heritable. The results complement those found in studies of $G$. fortis on another island and strengthen the view that these populations of Darwin's finches are frequently subjected to natural selection.
\end{abstract}

Received June 14, 1984. Accepted January 25, 1985

Species of Darwin's ground finches (Geospizinae) differ from each other in body size and bill dimensions, whereas they are remarkably similar in plumage coloration and behavioral displays associated with reproduction (Orr, 1945; Lack, 1947). Selection operates on variation among individuals in a population, thus variation in body size and bill dimensions must have been important in the evolution and speciation of Darwin's ground finches.

The aim of this paper is to examine natural selection at different stages of the life cycle in a population of Darwin's finches, Geospiza conirostris, which is unusually variable in bill size and shape. How are quantitative traits like bill size and shape related to fitness? Falconer (1981) points out that the fitness of an individual, as measured by its contribution of offspring to future breeding generations, is the outcome of all processes influencing survival, obtaining a mate, and rearing offspring. Fitness may therefore be divided into these component parts. There is likely to be a relationship between bill size and shape and some if not all of these fitness components. For instance bill size and shape in Darwin's finch species is known to influence their ability to forage on certain dry season foods (Abbott et al., 1977; Grant and Grant, 1980; Grant, 1981; Grant and Grant, 1981, 1982; Schluter, 1982a, 1982b; Schluter and Grant, 1982, 1984a, $1984 b$ ), and this could directly affect survival or the health of survivors at the end of the dry season, which would in turn influence their ability to compete for territories, gain mates, and reproduce.

In this study, I use Lande and Arnold's (1983) multivariate statistical method for measuring selection on quantitative traits. Their method is particularly suitable for this study because it takes into account correlations among characters, and it is known that phenotypic and genetic correlations among bill depth, bill length, and bill width in this population were 
large and positive at the time of the study (Grant, 1983). Thus, for example, direct selection to increase bill depth would indirectly increase bill length and bill width as well. Lande and Arnold's (1983) method of analysis reveals the target(s) of selection by separating the direct effects from the indirect effects caused by correlations among characters. I use their method of analysis to reveal the target(s) of selection and to identify the direction of selection on the bill characters for each fitness component. By doing this, I disclose some of the restraining factors and processes which must be overcome for a net change in bill dimensions to occur. This knowledge, in combination with a knowledge of heritabilities of the characters, helps us to understand and predict whether a given selection episode will or will not produce an evolutionary response in the next generation (Haldane, 1954; Lande and Arnold, 1983). Since many continuously variable characters in other organisms are polygenic, these findings are likely to be of broad significance.

\section{MATERIALs AND Methods}

The study area on the south side of Isla Genovesa constitutes $10 \%$ of the island area and is described in Grant and Grant (1980). Every breeding pair was known in this area in 1978, 1980, 1981, and 1982 ; less complete information is available for the years 1979 and 1983 .

Adults were captured in mist nets, measured, and uniquely banded with three coded color bands and one numbered metal band. Nestlings were measured and banded 8 days after hatching. Methods of measurements and repeatabilities of the measurements, which are high, are given in Grant (1983).

Selection Analysis. - Relative fitness is the absolute advantage of an individual in a fitness component divided by the mean of that component, so that the mean relative fitness in a population equals one. For example, the number of clutches a female produces in a season is transformed to a relative fitness component by dividing by the mean number of clutches of the population.

The directional selection differential $(s)$ is the difference in character means before and after selection and is measured in standard deviation units. It is produced by both the direct effects of selection on the character and the indirect effects of selection on correlated characters. It was calculated here as the covariance between relative fitness and the three characters, bill depth, bill length, and bill width. Significance levels for this analysis are for Spearman rank correlations of relative fitness with the characters (see Lande and Arnold, 1983).

The directional selection gradient $(\beta)$ is a measure of the direct force of selection on a character after removal of the indirect effects of other measured characters on fitness. It was calculated as the partial regression coefficient of relative fitness on the same three characters.

Before calculations of the directional selection gradients and differentials were made, all measurements except fitness were transformed to $\log _{e}$ values and then standardized to have unit variance. An assumption of the Lande and Arnold analysis is that characters follow a multivariate normal distribution (Price and Boag, 1985). Prior to each calculation, I tested the assumption by regressing one of the independent variables on the other two and plotting the residuals from the regression against the predicted values of the dependent variable. No departures from normality were found.

I was unable to use Lande and Arnold's (1983) analysis for calculating the stabilizing or disruptive selection gradient $(\gamma)$, because the sample sizes were too small. To detect stabilizing or disruptive selection, I restricted the calculations to single characters and used Levene's test (Van Valen, 1978).

Components of Fitness. - Adapting the method of Falconer (1981 p. 302), I list several components contributing to fitness and break them into the sub-components investigated in this study (Fig. 1). Directional selection differentials $(s)$ 
FITNESS

COMPONENTS SUB-COMPONENTS

SURVIVAL

SURVIVAL IN FIRST YEAR

LONGEVITY

MATING SUCCESS

OBTAINING A TERRITORY

OBTAINING A MATE

AGE AT FIRST REPRODUCTION

BREEDING SUCCESS

NUMBER OF CLUTCHES

NUMBER OF OFFSPRING

PREDATOR AVOIDANCE

PARENTAL CARE

FEEDING RATE

FIG. 1. Components of fitness for Geospiza conirostris (adapted from Falconer, 1981).

and directional selection gradients $(\beta)$ for bill depth, bill length, and bill width were calculated for each of the fitness subcomponents in Figure 1.

\section{RESUlTS \\ Survival}

First Year of Life. - The dry season (May-December) is a period of high mortality for birds less than a year old. As estimated from the known number of breeding pairs, the known number of fledglings produced, and the known number of both banded and unbanded birds breeding for the first time in the study area during 1978, 1980, 1981, and 1982, 88.9 percent of fledglings do not survive to breed. Most young birds disappear and probably die of starvation during their first dry season. This is further indicated by the low number of banded fledglings observed on the island after each dry season $(8-12 \%)$ and by the low number of unbanded males in first-year plumage on the study area (first year females cannot be distinguished from older females). Not only is food scarce at this time, but food items differ from those taken in the wet season and require different handling skills (Grant and Grant, 1979, 1980, 1982). The successful transition from wetseason to dry-season foraging for a bird in its first year could depend upon bill size and shape, as well as its ability to learn new feeding techniques. Therefore, I examined the relationship between survival and the characters bill depth, bill length, and bill width for birds in their first year.

Twenty-four birds banded in the nest in 1980 were recaptured and measured 100 days or more after hatching, at which time they had reached adult size (Grant, 1983). Those 16 which survived to the following year were given an absolute fitness value of 1 , those not seen again a value of 0 . Absolute fitnesses were converted to relative fitnesses, and directional selection differentials and gradients were calculated. None of the coefficients was significant; therefore directional selection did not occur.

However, the variance of each of the bill dimensions was greater among survivors than among non-survivors, particularly for bill length (mean \pm SE survivors $=14.53 \pm 0.30$, variance $=1.31$; of non-survivors $=14.39 \pm 0.23$, variance $=0.43$ ). The similarity in means of survivors and non-survivors and the greater variance in the survivors show a tendency in the direction of disruptive selection and not stabilizing selection. However the difference in variance between survivors and non-survivors is not significant at the two-tailed level (Levene's test, $t_{22}=1.72, P=0.10$ for bill length).

Longevity. - In contrast to the low survival of fledglings during their first year, survival of males and females after their first breeding season was high in periods without a drought (Grant and Grant, 1983). Absolute fitness was scored as 3 , 2 , or 1 for those individuals known to have lived through 3 or more, only 2 , or 
TABle 1. Standardized directional selection differentials $(s)$ and standard selection gradients $(\beta \pm$ standard error) for longevity of females $(N=26)$. * = significant at the 0.05 level.

\begin{tabular}{lrc}
\hline \hline Character & \multicolumn{1}{c}{$s$} & $\beta \pm$ SE \\
\hline Bill depth & -0.07 & $-0.11 \pm 0.16$ \\
Bill length & 0.12 & $0.17 \pm 0.08^{*}$ \\
Bill width & -0.07 & $-0.03 \pm 0.16$ \\
\hline
\end{tabular}

only 1 breeding seasons. The relationship between longevity and bill depth, bill length, and bill width was examined for each sex by calculating directional selection differentials and gradients. None of the coefficients for males was significant. For females, the directional selection gradient was significant for bill length (Table 1), the direction of selection being to increase bill length. The selection differential for bill length, however, was not significant. Table 1 shows that in the selection gradient the coefficients for bill depth and bill width were negative. Therefore, the lack of a significant selection differential for bill length can be attributed to the direct selection to increase bill length being counteracted by tendencies to decrease bill depth and bill width, all these bill dimensions being positively correlated with each other.

\section{Mating Success}

Obtaining a Territory.-Males establish their territories before obtaining females. Having bred in a territory, a male usually retains it for life. New males set up their territories around the established territories. There are two song types in the population, referred to as types $A$ and $B$ (Grant and Grant, 1979), and playback experiments indicate that males attempt to obtain territories adjacent to neighbors who sing a different song type from their own (Grant and Grant, 1983). Males that hold territories with an adjacent neighbors of unlike (heterotypic) song type have a significantly greater chance of obtaining a female, and they raise more young than do those males holding territories with only homotypic neighbors (Grant, 1984). From 1980-1982, but particularly in
TABLE 2. Standardized directional selection differentials $(s)$ and standardized selection gradients ( $\beta \pm$ standard error) for male recruits of the commoner song $B$ type obtaining territories with a heterotypic neighbor $(N=14)$. $*$ significant at the 0.05-0.01 level.

\begin{tabular}{llr}
\hline \hline Character & \multicolumn{1}{c}{$s$} & \multicolumn{1}{c}{$\beta \pm \mathrm{SE}$} \\
\hline Bill depth & $0.61^{*}$ & $0.59 \pm 0.63$ \\
Bill length & $0.63^{*}$ & $0.50 \pm 0.43$ \\
Bill width & 0.55 & $-0.37 \pm 0.71$ \\
\hline
\end{tabular}

1981 , song $B$ males were more abundant than song $A$ males (Grant and Grant, 1983; Grant, 1984). Consequently, there was more competition among new $B$ male recruits for territories with heterotypic neighbors than there was among $A$ male recruits in 1981. I examined the relationship between the success in obtaining a territory with a heterotypic neighbor and bill dimensions among $B$ male recruits in 1981. Absolute fitness was scored as 1 for the five new males that obtained territories with heterotypic neighbors and 0 for the nine that obtained territories with either only homotypic neighbors or no neighbors. Results are given in Table 2. In terms of the selection differentials, coefficients for bill depth and bill length were significant. Thus, males with deeper and longer bills obtained a territory with a heterotypic neighbor.

The analysis was repeated, with the substitution of new song $A$ males (rarer song type) that held territories with heterotypic neighbors for new song $B$ males with heterotypic neighbors. None of the coefficients was significant. Therefore, the direct selection to increase bill depth and length affected only the group of new males of the more common song type.

Obtaining a Mate. - Young males have a brown plumage and acquire an increasingly black plumage in successive molts (Grant and Grant, 1983). Males in fully black plumage obtain a female significantly earlier than do males in partially black plumage (Grant and Grant, 1983). Males that acquired fully black plumage within their first three years had significantly deeper, longer, and wider bills than 
TABLE 3. Standardized directional selection differentials $(s)$ and standardized selection gradients ( $\beta \pm$ standard error) for the order in which males obtained their females in the years $1980(N=23)$, $1981(N=26)$, and $1982(N=24) .^{*}=$ significant at the 0.05 level, ${ }^{* *}=$ significant at the 0.01 level.

\begin{tabular}{clcc}
\hline \hline Year & Character & $s$ & $\beta \pm \mathrm{SE}$ \\
\hline 1980 & Plumage & $0.38^{* *}$ & $0.32 \pm 0.08^{* *}$ \\
& Neighbor's & $0.30^{*}$ & $0.26 \pm 0.09^{* *}$ \\
& song type & & \\
& Bill depth & 0.05 & $-0.19 \pm 0.09$ \\
& Bill length & -0.15 & $0.12 \pm 0.10$ \\
& Bill width & -0.18 & $-0.21 \pm 0.19$ \\
1981 & Plumage & $0.32^{* *}$ & $0.27 \pm 0.10^{*}$ \\
& Neighbor's & $0.29^{* *}$ & $0.19 \pm 0.10$ \\
& song type & & \\
& Bill depth & 0.01 & $0.02 \pm 0.10$ \\
& Bill length & -0.01 & $-0.17 \pm 0.19$ \\
& Bill width & 0.01 & $0.08 \pm 0.19$ \\
Plumage & $0.23^{* *}$ & $0.20 \pm 0.10$ \\
& Neighbor's & $0.31^{* *}$ & $0.29 \pm 0.10^{* *}$ \\
& song type & & \\
& Bill depth & 0.18 & $0.05 \pm 0.10$ \\
& Bill length & 0.13 & $0.16 \pm 0.19$ \\
& Bill width & 0.13 & $0.23 \pm 0.19$ \\
\hline
\end{tabular}

did those which took longer to acquire black plumage (two-tailed $t$ tests, $N=19$, $P<0.05$ in each case). Because bill size and bill shape are associated both with obtaining territories and with acquiring fully black plumage, they could also be factors in mate selection by females. To test this possibility, I calculated the directional selection differential and gradient for the characters bill depth, bill length, bill width, plumage score, and song type of neighbors, using the sample of males that were known to have obtained a new female in the years 1980, 1981 , and 1982. Song type of neighbors was included for reasons mentioned in the previous section. Fitness was scored by the order, in weekly intervals, in which males obtained their females as indicated by the date of the first egg laid. None of the coefficients was significant for any of the bill dimensions in any of the three years (Table 3). Therefore, neither bill size or shape appeared to have been a factor in female choice of a mate. However, in all years, coefficients in the selection gradient and the selection differ-
TABLE 4. Standardized directional selection differentials $(s)$ and standardized selection gradients ( $\beta \pm$ standard error) for the number of clutches produced by females in $1978(N=13){ }^{*}=$ significant at the 0.05-0.01 level.

\begin{tabular}{ccc}
\hline \hline Character & $s$ & $\beta \pm \mathrm{SE}$ \\
\hline Bill depth & 0.02 & $-0.31 \pm 0.14$ \\
Bill length & 0.09 & $0.21 \pm 0.09^{*}$ \\
Bill width & 0.05 & $0.19 \pm 0.13$ \\
\hline
\end{tabular}

ential for plumage and song type of neighbors were significant (Table 3 ) indicating that song and plumage were factors in mate choice.

\section{Breeding Success}

Age at First Reproduction.-Females banded as nestlings later bred and were recaptured and measured as adults. The sample size of the largest cohort was too small for multivariate analysis $(N=7)$. A univariate analysis showed no significant correlation between age at first reproduction and any of the bill dimensions.

Number of Clutches Produced per Breeding Season. - In 1978, the year following the drought, the target and direction of selection was increased bill length for females producing the most clutches (Table 4). Direct selection to increase bill length was counteracted by selection towards a decrease in bill depth, resulting in no detectable selection differential for bill length, because bill length is positively correlated with bill depth. Analyses of females in $1980(N=18), 1981$ $(N=20)$, and $1982(N=36)$ gave similar results. In all years, the coefficients in the selection gradient for bill length were significant $(P<0.05)$ and positive; those for bill depth were not significant $(P<0.09)$ and were negative. Thus, in terms of clutch production, the target and direction of selection was increased bill length for females in all years. The consistency among years is due in part to certain individuals breeding successfully in all years.

Production of Offspring that Later Bred.-In terms of contributing the most 
TABle 5. Standardized directional selection differentials ( $s$ ) and standardized selection gradients $(\beta \pm$ standard error) for females $(N=36)$ producing offspring that later bred, divided by the number of clutches produced. $*=$ significant at the 0.05 level.

\begin{tabular}{lrc}
\hline \hline Character & \multicolumn{1}{c}{$s$} & $\beta \pm \mathrm{SE}$ \\
\hline Bill depth & -0.21 & $-0.57 \pm 0.32$ \\
Bill length & 0.17 & $0.43 \pm 0.19^{*}$ \\
Bill width & -0.16 & $0.13 \pm 0.29$ \\
\hline
\end{tabular}

offspring to future generations, the target and direction of selection was increased bill length for females. This result comes from a consideration of the number of banded fledglings that later bred produced by each female in the study area between 1978 and 1981 . I divided the number of offspring by the number of clutches the female produced to eliminate the effects of the different lengths of life of the females. Directional selection differentials and gradients are given in Table 5 . In the directional selection gradient, the coefficient for bill length was significant $(P<0.05)$ and positive; for bill depth, it was non-significantly negative $(P=0.09)$. Direct selection to increase bill length was apparently counteracted by selection on some other correlated character (e.g., bill depth; see above), as the coefficient for bill length in the directional selection differential was not significant. The same results were obtained when the analysis was repeated without an adjustment for number of clutches.

Thus, in terms of making the greatest contribution to the next breeding generation, the target and direction of selection was increased bill length between 1980 and 1983. The differential among females of different bill sizes originated in the number of clutches produced in a breeding season (previous section) and persisted through to the subsequent recruitment of the offspring to the breeding population.

The analysis was repeated for males but none of the coefficients was significant.

\section{Parental Care}

I was unable to measure many aspects of parental care including, for example, the feeding rate of young. However, I have data on nest predation which might be related to parental care. The nest predators on Isla Genovesa are short-eared owls (Asio flammeus) and mockingbirds (Nesomimus parvulus). We have shown previously that males breeding for the first time (and hence inexperienced) have their nests attacked significantly more frequently than do experienced breeders (Grant and Grant, 1983); ages and experience of the females were not known well enough to permit a similar analysis with them. The sample of males was therefore divided into those males that had bred at least once previously, and those that were breeding for the first time. Directional selection differentials and gradients were calculated separately for both groups. None of the coefficients was significant in either group in any year.

\section{Discussion}

The present study has yielded evidence of natural selection through an analysis using selection gradients. Selection has acted on bill characters or other characters with which they are correlated. The targets and directions of selection are different at different life history stages and are associated with different components of fitness. Among females, the target and direction of selection for three components of fitness was increased bill length. Among those males that competed for a territory, the males with long and deep bills were successful.

The method used in this study has the advantage of being able to distinguish the effects of female choice from those of male-male interactions, because they are separated in time (Arnold, 1983b). Males obtain their territories before mating with a female. In any year only a small number of males compete with each other for a territory with a heterotypic song neighbor. This is because previous breeders retain their territories, and first time breeding males of the rarer song type can 
more easily obtain a territory with a heterotypic song neighbor. It is therefore the first-time breeding males of the commoner song group that compete among themselves for a territory with a heterotypic neighbor. Among this small group, long-and deep-billed males had a selective advantage in obtaining the territories with a heterotypic song neighbor. Body size is correlated positively with all bill dimensions, particularly bill depth (Grant, 1983), and so this result could be due to individuals of large overall size winning male-male encounters. The selection differential for the first principal component, which is a multivariate characterization of size, was significant $(s=$ $0.58, P<0.05$ ). The first principal component was generated from the three bill dimensions, wing length, and tarsus length.

Females only pair with males holding territories. The results show that male bill size or shape were not cues used by females in their choice of a mate in this study. Instead fully black plumage (an age related trait) and a territory with a heterotypic song neighbor were factors influencing mating success. This mating advantage was translated into a reproductive advantage (Grant and Grant, 1983; Grant, 1984). The results are only partly consistent with those of a study of G. fortis on Daphne Major (Price, 1984b), where both bill dimensions and the degree of blackness in the plumage influenced mating success.

Endler (1985) has emphasized that there are very few studies in which it is known why selection occurs. Some of the forces of natural selection in the present study can be fairly easily interpretedmost notably the way in which survival in the dry season is related to bill dimensions by way of feeding skills and diets. At this season $G$. conirostris feed mainly on four food items that require the exercise of different skills. These are cracking hard Opuntia helleri seeds, extracting seeds from Opuntia fruits and eating the arils, bark-stripping trees to obtain arthropods, and opening decom- posing Opuntia pads to obtain insect larvae (Grant and Grant, 1979, 1980, 1982). Individuals using each one of these methods were compared with those individuals that had never been seen feeding in that way but had been observed feeding in the same area at the same time.

Five birds that opened Opuntia fruits to reach the enclosed seeds and their arils had significantly longer bills $(t=2.54$, $P<0.02)$ than the 26 birds never seen opening fruits. They did not differ significantly $(P>0.1)$ in the other two bill dimensions. In this case the bill dimensions associated with a skill is clearly identified. Both Opuntia seed-crackers and bark-strippers had significantly deeper, longer, and wider bills than those not feeding in these two ways (all $t$-tests, $P<0.05$, two-tailed). Here it appears that overall bill size, as opposed to one bill dimension or shape, separates those that did from those that did not feed in these two ways. The problem of character correlation clouds the interpretation; however, the Lande and Arnold technique can be used to help resolve it (e.g., Arnold, 1983a), as shown by the following extra calculations.

I gave an absolute fitness value of 1 to individuals seen feeding on the item and 0 to individuals never observed feeding in this way, and calculated what I shall call directional "trophic" differentials $(s)$ and gradients $(\beta)$. The five Opuntia seedcrackers (out of a total 36 birds) had significant and positive coefficients for bill depth $(s=1.03, P<0.05)$ and bill length $(s=1.04, P<0.05)$ in the trophic differential, and a non-significant coefficient for bill width ( $s=0.80, P>0.05$ ). Since none of the $\beta$ coefficients was significant, I interpret the selection differentials as indicating the importance of bill size as a whole as opposed to any single dimension. In contrast to this result, the 22 barkstrippers out of a total of 42 birds had a significant and positive coefficient for bill $\operatorname{depth}(\beta \pm \mathrm{SE}=0.50 \pm 0.25, P<0.05)$ and a non-significant and negative coefficients for bill width $(\beta \pm \mathrm{SE}=-0.48$ $\pm 0.26, P=0.07)$ and bill length $(P>$ 
0.1 ) in the trophic gradient, and no significant coefficients in the trophic differential. I interpret these results as indicating the importance of bill proportions in bark-stripping.

As at least three dry season food items are exploited most efficiently by birds with different bill sizes and shapes, the selective surface probably has more than one peak. This would account for the tendency towards disruptive selection on yearling birds in the dry season (Lande and Arnold, 1983; see also Schluter et al., 1985).

There is additional evidence of disruptive selection during the drought year of 1977 , but it is highly indirect. I cannot test directly for selection through the 1977 drought because the study only began in January 1978. However I can speculate on what might have happened from a knowledge of conditions at the end of the drought and by assuming that the 1982 breeders had the same characteristics as the 1976 pre-drought breeders. Comparison of the numbers of adult birds in the study area in 1978 and 1982 indicates an adult mortality during the 1977 drought of over 65 percent. There is no significant difference in the means of any of the bill dimensions between these two times (all $t$-tests, two tailed, $P>0.1$ ), but there is a difference in variance in bill depth; the 1978 adults (drought survivors) were significantly more variable than the 1982 adults (Levene's test, two tailed, $t_{83}=$ 2.03, $P<0.05$ ). The difference resides mainly in the females (Levene's test, $t_{38}=$ $2.43, P<0.05$ ). Males are more variable, but the difference is not significant (cf. Grant and Grant, 1979, 1983). Therefore, if the 1982 adults had characteristics similar to those of the 1976 adults, the greater variance in the drought survivors indicates that disruptive selection occurred during the 1977 drought. This result, being in the same direction as that found for young birds experiencing their first dry season, strengthens the view that dry conditions cause disruptive selection in this population.

When the fitness components are less directly associated with feeding, interpretation of results of the selection gradient analysis becomes more difficult. For example, in terms of longevity and breeding success, the target and direction of selection for females was increased bill length. However, in all these analyses, the coefficients in the selection gradient for bill depth were negative. This may result from some unidentified feeding advantage associated with long and shallow bills. Alternatively birds may gain an advantage from being small in body size, this being more strongly correlated with bill depth than with bill length (Grant, 1983) and from being able to more quickly reach a physiological level at which excess energy can be diverted from maintenance to reproduction (Downhower, 1976; Grant and Grant, 1980; Price, $1984 a$ ). This problem of interpretation illustrates the major limitation of the method of analysis (Arnold, 1983a; Lande and Arnold, 1983a). The true target of selection may be a character not included in the analysis; in this example it could be body size. If it is correlated with one that is included in the analysis, the results must be interpreted cautiously. In studies of birds in which bill dimensions are strongly and positively correlated with body size (Grant, 1983) but body size is not included in the analysis, it is best to recognize the possibility that selection may act independently on body size and bill size. Boag and Grant (1981) and Price et al. (1984) took this approach in their studies of $G$. fortis. In the present study, selection may have acted on both body size and bill size simultaneously.

Heritabilities of the three bill dimensions for this population at the time of this study were calculated previously (Grant, 1983). The three bill dimensions had high heritabilities and were positively genetically correlated with each other (Grant, 1983). Because bill dimensions are heritable, any shift in mean in a bill dimension caused by selection has the potential for evolutionary change (Haldane, 1954; Lande and Arnold, 1983). However, results of this study sug- 
gest three factors that minimize changes in bill dimensions over a life cycle. A tendency for the mean of one dimension to change is counteracted by 1) selection in the opposite direction on another, positively correlated, character, 2) the contrasting direction of selection in the two sexes, if there is a high genetic correlation between the sexes as there appears to be in G. fortis (Price, 1984a), and 3) selection in the opposite direction at a different stage of the life cycle (cf. Price and Grant, 1984). The first factor was especially important in this study, in that it prevented any selective shifts in mean phenotype from occurring, with the consequence that there was no opportunity for evolutionary change between generations during the study years. Net changes might require relaxation of selection at one stage and strong directional selection at another stage, as suggested by Price et al. (1984).

Arnold and Wade (1984) have shown how the portions of selection corresponding to particular fitness components can be summed to find the total selection acting on a trait over a life time of selection episodes. It would be rewarding to use their method for a large cohort of $G$. $\mathrm{co}$ nirostris followed throughout life, particularly if the life of this cohort spanned extreme climatic conditions-(e.g., extensive rain produced by an El Niño event and a drought year, both of which occur at least once a decade [Grant and Boag, 1980]).

The analysis of selection throws some light on the question of why bill dimensions are so variable in this population (Grant and Grant, 1983). Lande (1976) showed how depletion of variation through selection can be balanced by polygenic mutation. Grant and Price (1981) extended this scheme to explain the unusually high variation in body size and bill depth in $G$. fortis in terms of genetic input through hybridization combined with a low rate of depletion by selection. The high variation in $G$. conirostris can be similarly explained. The incidence of hybridization with sympat- ric congeners is approximately $1 \%$ (Grant and Grant, 1982, unpubl.). The high level of variation is depleted at a slow rate because the types of selection seen in this study tend to retain alleles. These are: 1) a tendency for disruptive selection during dry conditions, 2) selection in opposite directions on positively correlated bill dimensions; on the same dimension at different stages of the life cycle; and on the same dimension in the other sex. The result is the maintenance of a diversity of bill sizes and shapes.

\section{ACKNOWLEDGMENTS}

I am especially grateful to T. D. Price and P. R. Grant for assistance and advice at all stages of this study. I thank D. J. Anderson and T. C. Will for their invaluable work in the breeding seasons, and N. Grant and K. T. Grant for other field assistance. I also thank D. Schluter, J. N. M. Smith, and two anonymous reviewers for helpful criticism of the manuscript. The study was supported by the Dirección General de Desarrollo Forestal, Quito; The Charles Darwin Research Station; and the National Science Foundation, U.S.A. (grants DEB 77-23377 and DEB 79-21119 to P. R. Grant).

\section{Literature Cited}

Aвbott, I., L. K. Аввott, AND P. R. Grant. 1977. Comparative ecology of Galápagos Ground Finches (Geospiza Gould): Evaluation of the importance of floristic diversity and interspecific competition. Ecol. Monogr. 47:151-184.

ArNold, S. J. 1983a. Morphology, performance and fitness. Amer. Zool. 23:347-361.

- $1983 \mathrm{~b}$. Sexual selection: The interface of theory and empiricism, pp. 67-107. In P. P. G. Bateson (ed.), Mate Choice. Cambridge Univ. Press, Cambridge, U.K.

ArNold, S. J., AND M. J. WADE. 1984. On the measurement of natural and sexual selection: Applications. Evolution 38:720-734.

BoAG, P. T., AND P. R. GRANT. 1981. Intense natural selection in a population of Darwin's finches (Geospizinae) in the Galápagos. Science 214:82-85.

DOWNHOwer, J. F. 1976. Darwin's finches and the evolution of sexual dimorphism in body size. Nature 263:558-563.

ENDLER, J. A. 1985. Natural Selection in the Wild. Princeton Univ. Press, Princeton, NJ. In press. 
FALCONER, D. S. 1981. Introduction to Quantitative Genetics, 2nd. ed. Longman, N.Y.

Grant, B. R. 1984. The significance of song variation in a population of Darwin's finches. Behaviour 89:90-116.

Grant, B. R., AND P. R. Grant, 1979. Darwin's finches: Population variation and sympatric speciation. Proc. Nat. Acad. Sci. USA 76:23592363.

- 1981. Exploitation of Opuntia cactus by birds on the Galápagos. Oecologia 49:179-187.

1982. Niche shifts and competition in Darwin's finches: Geospiza conirostris and congeners. Evolution 36:637-657.

2. 1983. Fission and fusion in a population of Darwin's finches: An example of the value of studying individuals in ecology. Oikos 41 : 530-547.

Grant, P. R. 1981. The feeding of Darwin's finches on Tribulus cistoides (L.) seeds. Anim. Behav. 29:785-793.

-1983. Inheritance of size and shape in a population of Darwin's finches, Geospiza conirostris. Proc. Roy. Soc. Lond. B. 220:219-236.

Grant, P. R., AND P. T. BoAG. 1980. Rainfall on the Galápagos and the demography of Darwin's finches. Auk 97:227-244.

Grant, P. R., AND B. R. Grant. 1980. The breeding and feeding characteristics of Darwin's finches on Isla Genovesa, Galápagos. Ecol. Monogr. 50:381-410.

Grant, P. R., AND T. D. Price. 1981. Population variation in continuously varying traits as an ecological genetics problem. Amer.Zool. 21:795811.

HALDANE, J. B. S. 1954. The measurement of natural selection. Proc. IX Intl. Cong. Genet. 1: 480-487.

LACK, D. 1947. Darwin's Finches. Cambridge Univ. Press, Cambridge, U.K.

LANDE, R. 1976. The maintenance of genetic variability by mutation in polygenic characters with linked loci. Genet. Res. 26:221-225.

Lande, R., ANd S. J. ARnold. 1983. The measurement of selection on correlated characters. Evolution 37:1210-1226.
ORR, R. T. 1945. A study of captive Galápagos finches of the genus Geospiza. Condor 47:177201.

Price, T. D. 1984a. The evolution of sexual size dimorphism in Darwin's finches. Amer. Natur. 123:500-518.

. 1984b. Sexual selection on body size, territory and plumage variables in a population of Darwin's finches. Evolution 38:327-341.

Price, T. D., AND P. T. BoAg. 1985. Natural selection in birds. In P. A. Buckley and F. Cooke (eds.), Avian Genetics. Academic Press, London, U.K. In press.

Price, T. D., AND P. R. Grant. 1984. Life history traits and natural selection for small body size in a population of Darwin's finches. Evolution 38:483-494.

Price, T. D., P. R. Grant, H. L. GibBs, and P. T. BOAG. 1984. Recurrent patterns of natural selection in a population of Darwin's fincines. Nature 309:787-789.

SCHLUTER, D. 1982a. Distributions of Galápagos ground finches along an altitudinal gradient: The importance of food supply. Ecology 63:15041517.

- $1982 b$. Seed and patch selection by Galápagos ground finches: Relation to foraging efficiency and food supply. Ecology 63:1106-1120.

SChluter, D., AND P. R. GRANT. 1982. The distribution of Geospiza difficilis in relation to $G$. fuliginosa in the Galápagos islands: Test of three hypotheses. Evolution 36:1213-1226.

- 1984a. Ecological correlates of morphological evolution in a Darwin's finch, Geospiza difficilis. Evolution 38:856-869.

- 1984b. Determinants of morphological patterns in communities of Darwin's finches. Amer. Natur. 123:175-196.

SChluter, D., T. D. Price, AND P. R. Grant. 1985. Ecological character displacement in Darwin's finches. Science 227:1056-1059.

VAN VALEN, L. 1978. The statistics of variation. Evol. Theor. 4:33-43.

Corresponding Editor: J. A. Endler 